Disclaimer: This work has been published in IEEE Transactions on Ultrasonics, Ferroelectrics, and Frequency Control Vol. 61, No. 7, pp 1063-1074, July 2014.

http://dx.doi.org/10.1109/TUFFC.2014.3007

Copyright with IEEE. Personal use of this material is permitted. However, permission to reprint/republish this material for advertising or promotional purposes or for creating new collective works for resale or redistribution to servers or lists, or to reuse any copyrighted component of this work in other works must be obtained from the IEEE. This material is presented to ensure timely dissemination of scholarly and technical work. Copyright and all rights therein are retained by authors or by other copyright holders. All persons copying this information are expected to adhere to the terms and constraints invoked by each author's copyright. In most cases, these works may not be reposted without the explicit permission of the copyright holder. For more details, see the IEEE Copyright Policy 


\title{
Determination of Doping and Temperature Dependent Elastic Constants of Degenerately Doped Silicon from MEMS Resonators
}

\author{
Antti Jaakkola, Mika Prunnila, Tuomas Pensala, James Dekker and Panu Pekko \\ VTT Technical Research Centre of Finland, Espoo, Finland
}

\begin{abstract}
Elastic constants $c_{11}, c_{12}$ and $c_{44}$ of degenerately doped silicon are studied experimentally as a function of the doping level and temperature. First and second order temperature coefficients of the elastic constants are extracted from measured resonance frequencies of a set of MEMS resonators fabricated on seven different wafers doped with phosphorus (carrier concentrations $4.1,4.7$ and $7.5 \times 10^{19} \mathbf{c m}^{-3}$ ), arsenic $\left(1.7\right.$ and $\left.2.5 \times 10^{19} \mathrm{~cm}^{-3}\right)$, and boron $\left(0.6\right.$ and $\left.3 \times 10^{19} \mathrm{~cm}^{-3}\right)$, respectively. Measurements cover a temperature range from $-40^{\circ} \mathbf{C}$ to $+85^{\circ} \mathbf{C}$.

It is found that that the linear temperature coefficient of the shear elastic parameter $c_{11}-c_{12}$ is zero at n-type doping level of $n \sim 2 \times 10^{19} \mathbf{c m}^{-3}$, and that it increases to over $40 \mathbf{~ p p m} / \mathbf{K}$ with increasing doping. This observation implies that the frequency of many types of resonance modes, including extensional bulk modes and flexural modes, can be temperature compensated to first order. The second order temperature coefficient of $c_{11}-c_{12}$ is found to decrease by $40 \%$ in magnitude when n-type doping is increased from 4.1 to $7.5 \times 10^{19} \mathrm{~cm}^{-3}$.

Results of this study enable calculation of the frequency drift of an arbitrary silicon resonator design with an accuracy of \pm 25 ppm over $T=-40 \ldots 85^{\circ} \mathbf{C}$ at the doping levels covered in this work. Absolute frequency can be estimated with an accuracy of \pm 1000 ppm.
\end{abstract}

\section{INTRODUCTION}

Single-crystal silicon MEMS resonators are challenging quartz devices in timing and frequency control applications. The main disadvantage of silicon resonators is their high frequency drift of about $-30 \mathrm{ppm} / \mathrm{K}$, which needs to be compensated to make a stable reference. Heavy doping of silicon has recently been found as an attractive way to significantly reduce this temperature dependency. Doping dependency of the elastic constants of silicon can be explained as a free carrier effect. The band structure of Si depends on strain and, therefore, the charge carriers (introduced to the silicon crystal lattice with doping) redistribute between different bands under strain [1], [2]. This leads to strain dependency of the carriers' free energy and introduces doping dependent correction terms to the elastic constants. In $\mathrm{n}+\mathrm{Si}(\mathrm{p}+\mathrm{Si})$ the redistribution involves electrons (holes) that redistribute between different conduction band minima (valence band maxima).

Doping based temperature compensation of silicon resonators started with p-type doping [3], but n-type doping soon appeared as a viable alternative [4]. Our work with bulk mode resonators has shown that n-type doping is an effective and versatile way of tailoring the temperature behavior of silicon resonators; we have demonstrated resonators with their $f$ vs. $T$ turnover point near room temperature, overcompensated devices $(+18 \mathrm{ppm} / \mathrm{K})[5]$, and shown that n-type doping is applicable to virtually all resonance modes of practical importance [6]. Recently, resonators made of strongly n-type doped epitaxially grown silicon [7] have been reported.

The main contribution to the temperature dependent frequency drift of a resonator comes from the elastic constants of the resonator material. Thus, to optimize the thermal stability of a silicon MEMS resonator, a designer needs to know the temperature behavior of the elastic parameters of silicon; in particular the first and second order thermal derivatives of the elastic constants are of interest. However, experimental data of the temperature dependency of the elastic parameters of heavily doped silicon is limited; most usable results of ntype doped silicon have been published by Hall [8] for carrier concentration of $2 \times 10^{19} \mathrm{~cm}^{-3}$.

In this work, silicon elastic constants $c_{11}, c_{12}$ and $c_{44}$ are studied experimentally as a function of doping level and temperature. First and second order temperature coefficients of the elastic constants are extracted from the resonance frequencies of a set of MEMS resonators fabricated on seven different wafers with varied doping. In Section II the analysis method for extracting the unknown elastic parameters from the measured $f$ vs. $T$ curves of the resonators is introduced. The fabrication of the devices and the measurements are covered in Section III Results are presented in IV. Implications of the results are discussed in Section $\mathrm{V}$, concentrating on the aspects important for temperature compensation of MEMS resonators. Reliability of the elastic parameter extraction procedure is assessed, and, this provides a way to estimate how accurately the frequency and its thermal drift of an arbitrary resonator design can be calculated. An error analysis of the extracted elastic parameters is presented, and, additionally, MEMS resonator manufacturability aspects are covered.

\section{Methods}

A. Extraction of elastic constants from resonance frequencies

The frequency of an acoustic resonator is given by

$$
f=1 / L \times \sqrt{c / \rho},
$$

where $\rho, c$ and $L$ are the resonator material density, characteristic stiffness and characteristic length, respectively. The characteristic stiffness depends on the elastic constants $c_{11}$, $c_{12}$ and $c_{44}$ that can be solved from a set of measured 
resonance frequencies of different resonance modes when their functional dependency on constants $c_{i j}$ varies among the modes, and when there are three or more modes within the set. In our case, the set of two Lamé mode resonators and five length extensional (LE) modes in different orientations fulfill these conditions. The test resonator set, and their exemplary sensitivities on the $c_{i j}$ parameters are illustrated Fig. 11, and micrographs of the two types of resonators are shown in Fig. 3(a). Additional constraints that lead to the selection of this particular set of devices were: 1) the resonators had to be actuated electrostatically over vertical coupling gaps, 2) air damping needed to low enough to allow detection of resonances in atmospheric pressure, 3) the resonators had to be relatively large in lateral dimensions to minimize effects from processing inaccuracies, 4) the resonance frequencies and their sensitivities on $c_{i j}$ should be insensitive to device thickness variations (see error $E_{5}$ in Section V-D, and 5) the number of different resonator types had to be relatively large in comparison with the three unknowns $c_{i j}$ to allow assessment of the reliability of the results (Section $\overline{\mathrm{V}-\mathrm{C}}$.

\begin{tabular}{|c|c|c|c|c|c|}
\hline \multicolumn{2}{|l|}{ (a) } & \multirow[t]{2}{*}{$f\left(c_{11}, c_{12}, c_{44}\right)$} & $\frac{1}{f} \frac{\partial f}{\partial c_{11}}$ & $\frac{1}{f} \frac{\partial f}{\partial c_{12}}$ & $\frac{1}{f} \frac{\partial f}{\partial c_{44}}$ \\
\hline & & & \multicolumn{3}{|c|}{$[\mathrm{ppm} / \mathrm{MPa}]$} \\
\hline Lamé $0^{\circ}$ & & $\frac{1}{\sqrt{2} L} \sqrt{\frac{c_{44}}{\rho}}$ & 0 & 0 & 6.33 \\
\hline $\operatorname{LE} 0^{\circ}$ & 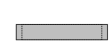 & $\begin{array}{ll}- & - \\
-1\end{array}$ & 1.77 & -0.80 & 3.33 \\
\hline LE $11.25^{\circ}$ & $r$ & - & 2.30 & -1.37 & 2.72 \\
\hline LE $22.5^{\circ}$ & & - & 3.37 & -2.53 & 1.46 \\
\hline $\operatorname{LE} 33.75^{\circ}$ & & - & 4.27 & -3.50 & 0.40 \\
\hline $\operatorname{LE} 45^{\circ}$ & & - & 4.61 & -3.87 & 0 \\
\hline Lamé $45^{\circ}$ & & $\frac{1}{\sqrt{2} L} \sqrt{\frac{\left(c_{11}-c_{12}\right) / 2}{\rho}}$ & 5.10 & -5.10 & 0 \\
\hline
\end{tabular}

(b)

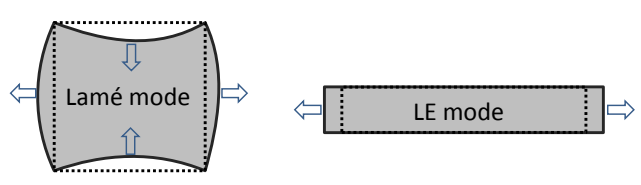

Figure 1. (a) Determination of the elastic constants $c_{11}, c_{12}$ and $c_{44}$ is based on seven resonance modes, whose frequencies have different dependencies on the $c_{i j}$ parameters. Alignment of the resonators is varied from [110] to [100]. The table contains the analytical formulas for the resonance frequency $f\left(c_{11}, c_{12}, c_{44}\right)$ - which exist only for the two Lamé modes - and the sensitivities $1 / f \times \partial f / \partial c_{i j}$ for each mode. These exemplary sensitivities have been calculated at a linearization point of $\left(c_{11}, c_{12}, c_{44}\right)=(163,65,79) \mathrm{GPa}$ using the finite element approach outlined in Section II-B (zero angular alignment error and device layer thickness $15 \mu \mathrm{m}$ of has been assumed). The listed numbers only illustrate the character of the variation of the sensitivies within the set of modes. For individual wafers, the sensitivities differ due to different linearization points, device layer thicknesses and angular misalignments, respectively. (b) Illustration of the mode shapes of the Lamé/LE resonances.

The experimental data consists of measured resonance frequencies at different temperatures for all seven resonance modes $f_{k}^{\exp }(T)(k=1, \ldots, 7)$. Let us denote the corresponding theoretical estimates containing the $c_{i j}$ dependencies obtained through FEM modelling - as $f_{k}^{\text {th }}\left(c_{11}, c_{12}, c_{44}\right)$. We use an approach of first matching $f_{k}^{\exp }$ and $f_{k}^{\text {th }}$ at $T_{0}=20^{\circ} \mathrm{C}$ by numerical minimization of

$$
g\left(c_{i j}\right)=\sum_{k}\left[f_{k}^{\exp }-f_{k}^{\mathrm{th}}\left(c_{i j}\right)\right]^{2}
$$

to find elastic parameters $c_{i j}\left(T_{0}\right)$, and then linearize (1) to obtain the relation

$$
\frac{\delta f_{k}^{\exp }(T)}{f_{k 0}^{\exp }}=\frac{1}{f_{k 0}^{\text {th }}} \sum_{i j} \frac{\partial f_{k}^{\text {th }}}{\partial c_{i j}} \delta c_{i j}(T)+\frac{1}{2} \frac{\delta L}{L}(T) .
$$

Here $\delta c_{i j}(T)$ are the unknown changes in elastic parameters, $\delta f_{k}^{\exp }(T)$ are the measured frequency differences, while $f_{k 0}^{\exp }$ and $f_{k 0}^{\text {th }}$ are shorthands for $f_{k}^{\exp }\left(T_{0}\right)$ and $f_{k}^{\text {th }}\left(c_{i j}\left(T_{0}\right)\right)$. Sensitivities $\partial f_{k}^{\text {th }} / \partial c_{i j}$ are calculated from the theoretical estimates. The last term accounts for thermal expansion, and it has been obtained by employing the isotropic of nature of length changes for silicon. We use a 3rd order expansion for this term

$$
\frac{1}{2} \frac{\delta L}{L}(T)=\left(\alpha_{1} \Delta T+\alpha_{2} \Delta T^{2}+\alpha_{3} \Delta T^{3}\right) / 2,
$$

where values of $\alpha_{1}=2.84 \times 10^{-6} \mathrm{~K}^{-1}, \alpha_{2}=8.5 \times 10^{-9} \mathrm{~K}^{-2}$ and $\alpha_{3}=-32 \times 10^{-12} \mathrm{~K}^{-3}$ are assumed. These expansion coefficients are based on the values reported for undoped silicon in Ref. [9]; thus, it is assumed that thermal expansion is not affected by doping. The assumption is supported by our measurements with mechanical dilatometry (see Section V-E).

In matrix form (3) can be denoted as

$$
\delta \mathbf{f}^{\exp }(T)=A \cdot \delta \mathbf{c}(T)+\beta(T) .
$$

where $\delta \mathbf{f}^{\exp }$ contains the relative frequency changes, and elements of the sensitivity matrix $A$ are defined as

$$
a_{k n}=\frac{1}{f_{k 0}^{\text {th }}} \frac{\partial f_{k}^{\text {th }}}{\partial c_{n}}, n=11,12,44 ; k=1, \ldots, 7 .
$$

Sensitivity matrix elements are illustrated in Fig. 1. One should note that (6) depends on the linearization point at which it is evaluated.

The changes in elastic parameters $\delta \mathbf{c}(T)$ can be solved as a least squares fit from (5):

$$
\delta \mathbf{c}(T)=\left(A^{T} A\right)^{-1} A^{T}\left[\delta \mathbf{f}^{\exp }(T)-\beta(T)\right] .
$$

\section{B. Numerical modelling}

Numerical estimates of the modal frequencies $f_{k}^{\text {th }}\left(c_{11}, c_{12}, c_{44}\right)$ were calculated by finite element analysis with Comsol Multiphysics. Resonance frequencies were obtained with modal analysis of full 3D geometries of the devices including the anchoring regions, see illustration of the finite element mesh in Fig 3 b). Nominal thickness of $15 / 24 \mu \mathrm{m}$ of the wafers were used in the calculations, see Table [I. Maximum size of the mesh elements was $20 \times 20 \times 4 \mu \mathrm{m}^{3}$.

Calculation was performed for parameters $c_{11}, c_{12}$ and $c_{44}$ spanning ranges of $[160 \ldots 168 \mathrm{GPa}],[63 \ldots 68 \mathrm{GPa}]$ and 
$[78 \ldots 80 \mathrm{GPa}]$, respectively. The ranges were discretized to a grid of $5 \times 5 \times 5$ points. Values were stored in tables, and later retrieved for evaluation of Eqs. 2 and 6 . Cubic interpolation was used for evaluation of $f_{k}^{\text {th }}\left(c_{11}, c_{12}, c_{44}\right)$ between grid points. The discretization was verified to be dense enough for accurate evaluation of the derivatives of (6). Simulations took into account different angular misalignments of the wafers.

\section{Measurement of angular misalignment}

In practice, fabrication of the devices results in a small deviation of the resonator orientation from the intended alignment with the crystal axes, which can affect accuracy of the extraction of elastic parameters. This deviation, or angular misalignment $\Delta \theta$, was determined using the method illustrated in Fig. 2. Due to silicon anisotropy, the resonance frequency of a LE mode beam resonator increases by $\sim 10 \%$ when resonator alignment is rotated from [100] to [110]. Between these directions, i.e., at $\pm 22.5^{\circ}$ from [110], the resonance frequency is most sensitive to angular misalignment with $\Delta f / \Delta \theta \sim \pm 460 \mathrm{ppm} / 0.1 \mathrm{deg}$. Copies of two LE resonators identical in dimensions, but oriented $45^{\circ}$ to each other, both at the most sensitive orientation of $\pm 22.5^{\circ}$ were included on the wafers. The angular misalignment could be deduced from the up/down frequency shifts $\pm \Delta f$ of these resonators.

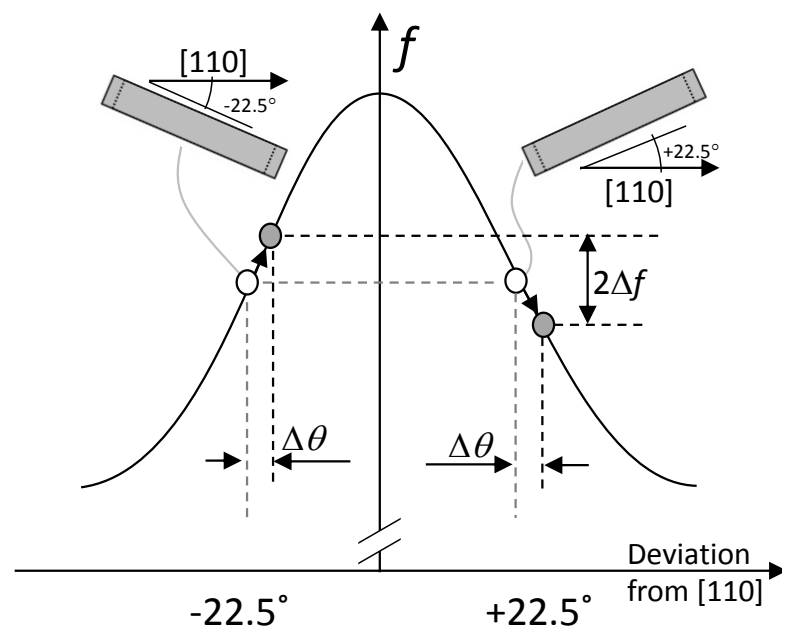

Figure 2. In-plane angular misalignment of the wafers can be deduced from the difference of the resonance frequencies of two types of LE beam resonators, which are designed at an angle of $\pm 22.5^{\circ}$ from [110] direction. In-plane rotation of the resonators shifts the resonance frequencies up/down by $\pm 460 \mathrm{ppm} / 0.1 \mathrm{deg}$.

\section{EXPERIMENTAL}

The resonators (Fig. 3(a)) were fabricated on seven different 150-mm C-SOI wafers (Silicon-On-Insulator wafers with pre-etched cavities [11]) manufactured in co-operation with Okmetic Oyj. The handle wafers with DRIE etched cavities were thermally oxidized before they were fusion bonded to the device wafers. Device layers were fabricated from 100oriented wafers grown with the Czochralski method. The resonator fabrication process started with the C-SOI wafers with circular cavities of a diameter of $500 \mu \mathrm{m}$ for each resonator.
Table I

DETAILS OF THE WAFERS FOR THE SILICON DEVICE LAYERS. CARRIER CONCENTRATIONS WERE CALCULATED FROM THE RESISTIVITY SPECIFICATION USING REF. [10]. CARRIER CONCENTRATION RANGES ARE INCLUDED AS ERROR BARS IN FIG. 8 ANGULAR MISALIGNMENT WAS MEASURED USING THE METHOD DESCRIBED IN SECTION II-C

\begin{tabular}{|c|c|c|c|c|c|c|c|c|c|}
\hline \multirow[b]{2}{*}{ wafer id } & \multirow[b]{2}{*}{ dopant } & \multicolumn{2}{|c|}{$\begin{array}{c}\text { specified } \\
\text { resistivity } \\
{[\mathrm{mOhm} \mathrm{cm]}}\end{array}$} & \multicolumn{3}{|c|}{$\begin{array}{c}\text { calculated carrier } \\
\text { concentration } \\
{\left[10^{19} \mathrm{~cm}^{-3}\right]}\end{array}$} & \multirow{2}{*}{$\begin{array}{l}\text { angular } \\
\text { alignment } \\
\text { error } \\
\text { [deg] }\end{array}$} & \multirow{2}{*}{$\begin{array}{c}\text { device } \\
\text { layer } \\
\text { thickness } \\
{[\mu \mathrm{m}]}\end{array}$} & \multirow{2}{*}{$\begin{array}{c}\text { total } \\
\text { thickness } \\
\text { variation } \\
{[\mu \mathrm{m}]}\end{array}$} \\
\hline & & $\min$ & $\max$ & $\min$ & $\max$ & avg & & & \\
\hline$\overline{B 3}$ & $B$ & 3.49 & 3.66 & 2.88 & 3.04 & 2.96 & -0.6 & 23.8 & 3.1 \\
\hline B0.6 & $B$ & 10 & 20 & 0.33 & 0.86 & 0.60 & -0.1 & 15.6 & 3.5 \\
\hline As1.7 & As & 3.96 & 4.36 & 1.55 & 1.77 & 1.66 & 0.3 & 15.4 & 2.7 \\
\hline As2.5 & As & 2.94 & 3.08 & 2.39 & 2.52 & 2.46 & -0.6 & 14.5 & 2.5 \\
\hline P4.1 & $P$ & 1.67 & 1.76 & 3.98 & 4.22 & 4.10 & 0.0 & 14.6 & 2.6 \\
\hline P4.7 & $P$ & 1.47 & 1.59 & 4.45 & 4.86 & 4.66 & 1.6 & 14.5 & 3.7 \\
\hline P7.5 & $\mathrm{P}$ & 0.95 & 1.05 & 7.05 & 7.89 & 7.47 & 0.5 & 14.5 & 1.7 \\
\hline
\end{tabular}
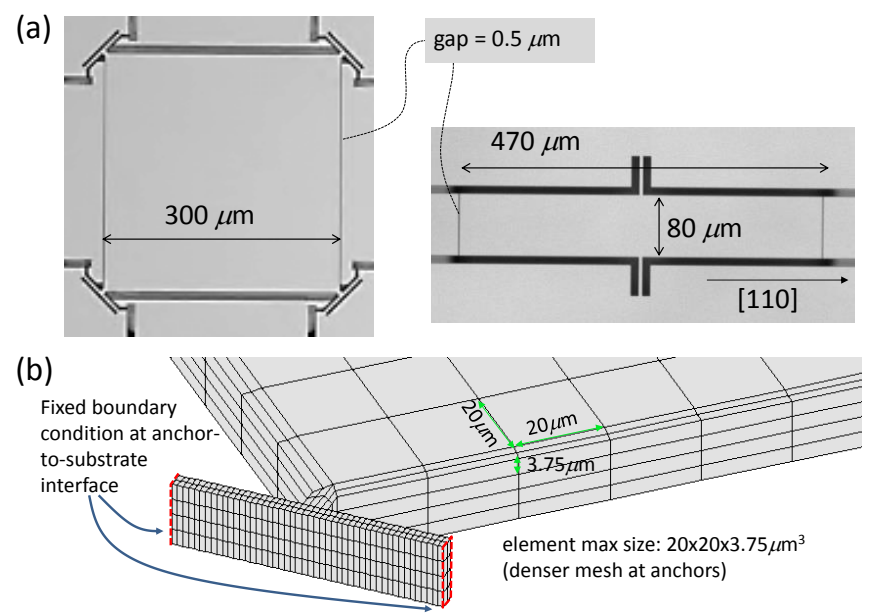

Figure 3. (a) Micrographs of Lamé and LE mode resonators. (b) Illustration of the finite element mesh at one corner of the Lamé mode resonator. Meshing was done in similar fashion for the LE mode resonator models.

The process flow consisted of two lithographic layers: 1) Al contact metallization and patterning 2) DRIE release etch producing vertical gaps of minimum nominal width of $0.5 \mu \mathrm{m}$.

Dopant (B, P, and As) concentrations of the wafers for the silicon device layer were varied according to Table I] Carrier concentration range for each wafer was calculated from the specified resistivity range using conversion method of Ref. [10]. Device layer nominal thickness was $15 \mu \mathrm{m}(24 \mu \mathrm{m}$ for wafer B3), and the manufacturer specified C-SOI stack total thickness variation (including the handle wafer) was within $\pm 2 \mu \mathrm{m}$ for all wafers.

As the wafers featured pre-etched cavities, it was possible to fabricate monolithic resonators without a grid of release etch holes within the devices, and thus the elastic properties of the resonators could be accurately modelled. In our previous studies [5], existence of release etch holes was a source of uncertainty for the determination of the elastic constants.

The resonators were measured on wafer level in atmospheric pressure on a Cascade Summit probe station using a HP 4294A impedance analyzer. A two-needle probe card was used for the measurements, and an open-short-load calibration was performed at $T=40^{\circ} \mathrm{C}$ in the beginning of the measurement. Measurements were done in the four-terminal pair configuration with four 2-m BNC cables, and the two 


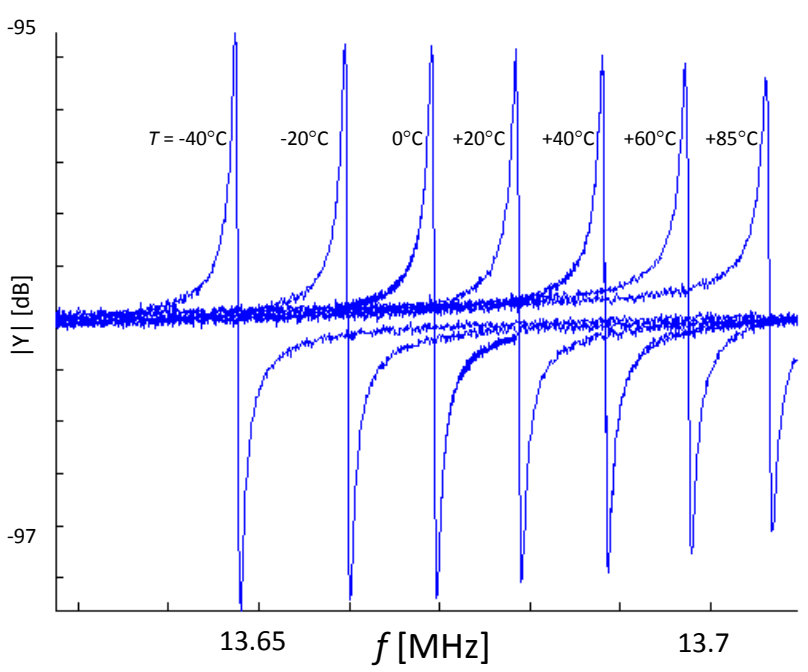

Figure 4. Measured admittance traces of the Lame- $45^{\circ}$ resonators on wafer P7.5 measured at different temperatures.

end connections to the probe needles were $\sim 15 \mathrm{~cm}$ long. A DC bias voltage of $40 \mathrm{~V}$ was applied between the resonator and the electrodes for electromechanical coupling. Effect on the resonance frequencies from the DC bias was negligible because of the relatively wide coupling gaps and the high mechanical spring constant of the resonance modes. The excitation $\mathrm{AC}$ voltage level was set to $1 \mathrm{~V}$ to maximize signalto-noise ratio. The resonators still operated at their linear regime due to the weak electromechanical coupling. Measured devices were located near the wafer center. Quality factors of $Q \sim 10,000$ were measured for all resonance modes, and the resonance frequencies were extracted by fitting a BVD equivalent circuit to the the measured admittances. Example traces are shown in Fig. 4

The wafer was held on a temperature controlled chuck, whose temperature was varied from $-40^{\circ} \mathrm{C}$ to $+85^{\circ} \mathrm{C}$ with seven steps (for wafer As1.7 the highest temperature was $\left.80^{\circ} \mathrm{C}\right)$. The specified temperature accuracy of the system (Temptronic TP3200A) including the temperature controller and the chuck was $\pm 0.5^{\circ} \mathrm{C}$. A 15 minute stabilization period followed after each temperature change before probing of the resonators was started; the chuck temperature was well stabilized in less than 10 minutes for all temperature steps. Clean dry air flow at a rate of $30 \mathrm{l} / \mathrm{min}$ was used for purging. The effect from room temperature gas flow to resonator temperature was found to be smaller than the specified uncertainty of $\pm 0.5^{\circ} \mathrm{C}$ by the following comparison: Lame- $45^{\circ}$ resonator $f$ vs. $T$ curves on wafer B0.6 were compared to corresponding data from a similar wafer that was wafer level encapsulated by a silicon/glass wafer (encapsulation method is described in Ref. [12]). Encapsulated resonators can be assumed to be free from thermal gradients caused by the gas flow, but it could potentially affect temperature of resonators on uncapped wafers like B0.6. $f$ vs. $T$ curves of resonators near the wafer center on these two wafers were found to overlap with each other within $15 \mathrm{ppm}$, implying that device temperatures were within $\sim 0.5^{\circ} \mathrm{C}$ with each other (assuming identical

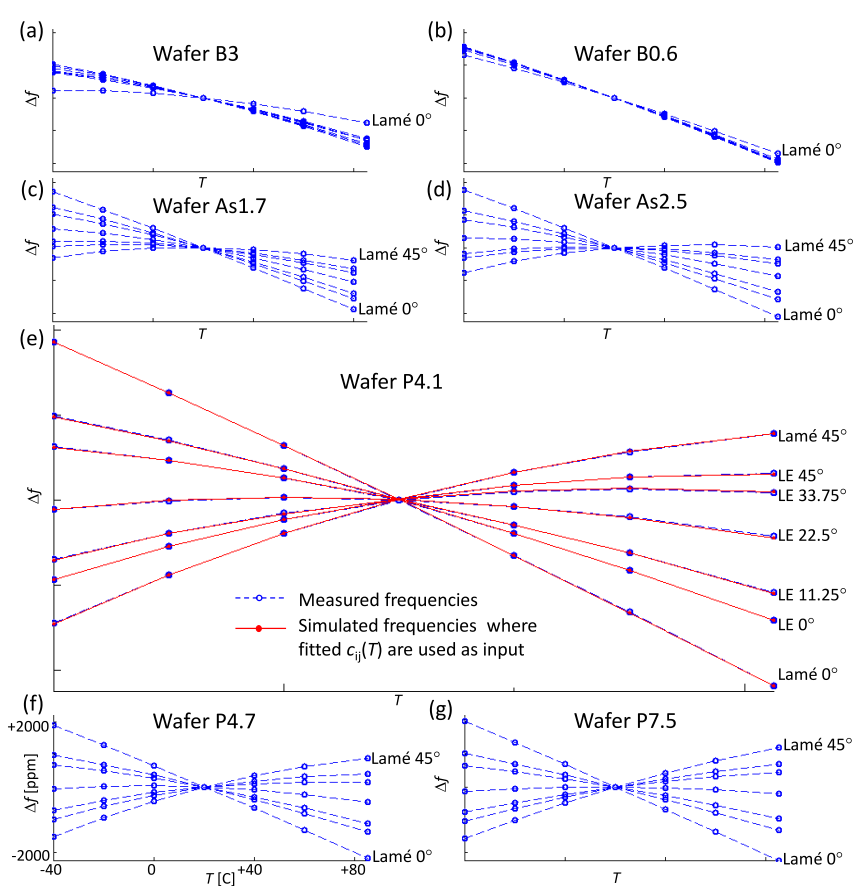

Figure 5. (a) $-(\mathrm{g})$ : Measured $f$ vs. $T$ data of all resonance modes on all wafers is shown with blue open circles. Dashed blue lines are second order polynomial fits to the data; fit coefficients are collected in Table II All plots have the similar scaling of axes. (e): Experimental data from wafer P4.1 has been overlaid with corresponding numerical estimates $f_{k}^{\text {th }}(T)$ which use the fitted parameters $c_{i j}(T)$ as an input (red lines with dots). The overlap is shown in more detail in Fig. 9 b).

temperature coefficients for the resonators on both wafers (see Table III.

\section{RESUlts}

Measured frequency vs. temperature curves are shown for all modes on all wafers in Fig. 5, and the related temperature coefficients are collected in Table II On the weakest doped wafer B0.6 all $f$ vs. $T$ curves lie almost on top of each other, and the linear temperature coefficients are near $-30 \mathrm{ppm} / \mathrm{K}$. On wafer B3, the slopes of the curves are decreased in magnitude, and the biggest change is observed for the Lamé- $0^{\circ}$ mode. On n-type doped wafers larger effects are observed. The slope of the $f$ vs. $T$ curve of the Lamé $-45^{\circ}$ mode is gradually increased with increasing doping, and above $2 \times 10^{19} \mathrm{~cm}^{-3}$ the slopes are positive. Lame $-0^{\circ}$ mode is almost unaffected by doping, and the $f$ vs. $T$ curves of the LE modes span the region between the two Lamé modes.

Frequencies of $>20$ LE beam resonators were measured on each wafer for determination of the angular misalignment as described in Section [II-C Results are tabulated in Table [] Figure 6 shows an example of the resonance curves for wafer P7.5.

The elastic parameters $c_{i j}(T)$ were extracted from the measured frequency data using the least squares method of Section II-A Results are shown in Fig. 7 The magnitude of the elastic constants is observed to decrease upon increased doping, except for the $c_{12}$ elastic constant which gets larger with increasing n-type doping. For closer investigation of 
Table II

TEMPERATURE COEFFICIENTS OF FREQUENCY $\left(f_{0}, a\right.$ AND $b$ ) OF THE RESONANCE MODES OF FIG. 5. FIT WAS DONE TO POLYNOMIAL $f(T)=f_{0}\left[1+a\left(T-T_{0}\right)+b\left(T-T_{0}\right)^{2}\right]$, WHICH WAS CENTERED AT $T_{0}=25^{\circ} \mathrm{C}$. THE FITS REPRODUCED THE $f$ VS. $T$ CURVES TO WITHIN \pm 10 PPM FOR ALL CASES.

\begin{tabular}{|c|c|c|c|c|c|c|c|c|c|c|c|c|}
\hline \multicolumn{3}{|c|}{ Wafer B3 } & \multicolumn{3}{|c|}{ Wafer B0.6 } & \multicolumn{3}{|c|}{ Wafer As1.7 } & \multicolumn{3}{|c|}{ Wafer As2.5 } & \multirow[b]{2}{*}{$\begin{array}{c}b \\
{\left[\mathrm{ppb} / \mathrm{K}^{2}\right]}\end{array}$} \\
\hline Mode & $\begin{array}{c}\mathrm{fo} \\
{[\mathrm{MHz}]}\end{array}$ & $\begin{array}{c}\mathrm{a} \\
{[\mathrm{ppm} / \mathrm{K}]}\end{array}$ & $\begin{array}{c}b \\
{\left[\mathrm{ppb} / \mathrm{K}^{2}\right]}\end{array}$ & $\begin{array}{c}\mathrm{f0} \\
{[\mathrm{MHz}]}\end{array}$ & $\begin{array}{c}\mathrm{a} \\
{[\mathrm{ppm} / \mathrm{K}]}\end{array}$ & $\begin{array}{c}b \\
{\left[\mathrm{ppb} / \mathrm{K}^{2}\right]}\end{array}$ & $\begin{array}{c}\mathrm{fO} \\
{[\mathrm{MHz}]}\end{array}$ & $\begin{array}{c}\mathrm{a} \\
{[\mathrm{ppm} / \mathrm{K}]}\end{array}$ & $\begin{array}{c}b \\
{\left[\mathrm{ppb} / \mathrm{K}^{2}\right]}\end{array}$ & $\begin{array}{c}\mathrm{f0} \\
{[\mathrm{MHz}]}\end{array}$ & $\begin{array}{c}\mathrm{a} \\
{[\mathrm{ppm} / \mathrm{K}]}\end{array}$ & \\
\hline Lamé 0 & 13.68 & -8.3 & -64 & 13.77 & -24.5 & -37 & 13.76 & -30.4 & -25 & 13.75 & -31.1 & -23 \\
\hline LE $0^{\circ}$ & 9.02 & -16.6 & -52 & 9.07 & -27.8 & -33 & 9.04 & -24.0 & -44 & 9.03 & -22.2 & -43 \\
\hline LE $11.25^{\circ}$ & 8.81 & -17.3 & -50 & 8.87 & -28.0 & -33 & 8.85 & -20.8 & -49 & 8.80 & -17.9 & -53 \\
\hline LE $22.5^{\circ}$ & 8.39 & -18.8 & -49 & 8.45 & -28.3 & -34 & 8.41 & -14.4 & -66 & 8.36 & -9.9 & -69 \\
\hline LE $33.75^{\circ}$ & 8.04 & -19.9 & -47 & 8.09 & -28.6 & -34 & 8.03 & -8.9 & -78 & 7.99 & -3.0 & -83 \\
\hline LE $45^{\circ}$ & 7.92 & -20.4 & -47 & 7.95 & -28.7 & -34 & 7.88 & -6.7 & -85 & 7.86 & -0.8 & -85 \\
\hline \multirow[t]{2}{*}{ Lamé $45^{\circ}$} & 10.96 & -17.2 & -52 & 11.02 & -27.1 & -37 & 10.91 & -1.8 & -94 & 10.86 & 5.6 & -98 \\
\hline & \multicolumn{3}{|c|}{ Wafer P4.1 } & \multicolumn{3}{|c|}{ Wafer P4.7 } & \multicolumn{3}{|c|}{ Wafer P7.5 } & & & \\
\hline Mode & $\begin{array}{c}\mathrm{fO} \\
{[\mathrm{MHz}]}\end{array}$ & $\begin{array}{c}\mathrm{a} \\
{[\mathrm{ppm} / \mathrm{K}]}\end{array}$ & $\begin{array}{c}b \\
{\left[\mathrm{ppb} / \mathrm{K}^{2}\right]}\end{array}$ & $\begin{array}{c}\mathrm{fO} \\
{[\mathrm{MHz}]}\end{array}$ & $\begin{array}{c}\mathrm{a} \\
{[\mathrm{ppm} / \mathrm{K}]}\end{array}$ & $\begin{array}{c}b \\
{\left[\mathrm{ppb} / \mathrm{K}^{2}\right]}\end{array}$ & $\begin{array}{c}\mathrm{fO} \\
{[\mathrm{MHz}]}\end{array}$ & $\begin{array}{c}\mathrm{a} \\
{[\mathrm{ppm} / \mathrm{K}]}\end{array}$ & $\begin{array}{c}\mathrm{b} \\
{\left[\mathrm{ppb} / \mathrm{K}^{2}\right]}\end{array}$ & & & \\
\hline Lamé 0 & 13.74 & -32.5 & -20 & 13.72 & -32.7 & -17 & 13.68 & -34.5 & -12 & & & \\
\hline LE $0^{\circ}$ & 9.00 & -19.5 & -42 & 8.99 & -19.0 & -39 & 8.95 & -18.9 & -26 & & & \\
\hline LE $11.25^{\circ}$ & 8.79 & -14.1 & -51 & 8.83 & -14.7 & -46 & 8.75 & -13.2 & -31 & & & \\
\hline LE $22.5^{\circ}$ & 8.34 & -3.0 & -68 & 8.39 & -3.7 & -62 & 8.30 & -0.8 & -41 & & & \\
\hline LE $33.75^{\circ}$ & 7.96 & 5.8 & -82 & 7.98 & 6.4 & -77 & 7.89 & 9.6 & -48 & & & \\
\hline LE $45^{\circ}$ & 7.81 & 9.4 & -87 & 7.80 & 10.6 & -84 & 7.74 & 13.7 & -52 & & & \\
\hline Lamé $45^{\circ}$ & 10.79 & 17.2 & -98 & 10.75 & 18.6 & -94 & 10.66 & 22.1 & -57 & & & \\
\hline
\end{tabular}

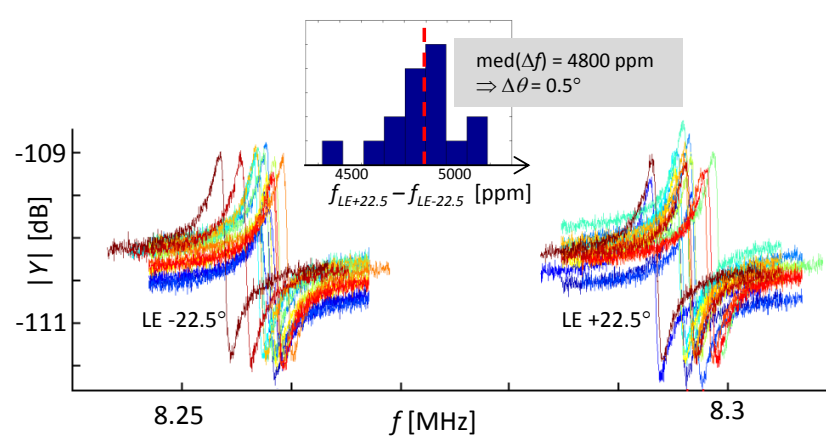

Figure 6. Admittance traces of $32 \mathrm{LE}$ mode beam resonators (16 pairs) on wafer P7.5 at $\pm 22.5^{\circ}$ offset from the [110] direction. Closest pairs (one resonator with $+22.5^{\circ}$ offset and the other with $-22.5^{\circ}$, respectively) have been colored similarly, and all pairs have different colors. Inset: Distribution of the frequency differences between the closest pairs. Angular misalignment is calculated from the median of this distribution (see Section [II-C.

the thermal dependency of the $c_{i j}(T)$ curves, second-order polynomials centered at $T_{0}=25^{\circ} \mathrm{C}$ were fitted to the elastic parameter data as

$$
c_{i j}(T)=c_{i j}^{0}\left[1+a_{i j}\left(T-T_{0}\right)+b_{i j}\left(T-T_{0}\right)^{2}\right],
$$

where $a_{i j}$ and $b_{i j}$ are the first-order and second-order temperature coefficients, respectively, and $c_{i j}^{0}$ is the constant term A second-order expansion of $c_{i j}(T)$ was found to be valid to within $\pm 20 \mathrm{ppm}$ for all $c_{i j}(T, n)$. The results are collected in Figs. 8(a)-(1) and in Table III One should note that, in Fig. 8, we have chosen to accommodate data points from both nand p-type doped wafers within same axes by representing $\mathrm{p} / \mathrm{n}$ type doping with negative/positive carrier concentrations. Observations are discussed in the following section.

\footnotetext{
${ }^{1}$ One should notice that the least squares method of Section II-A uses $T=$ $20^{\circ} \mathrm{C}$ as the linearization point, since it was one of the measurement points. However, expansions of 8 and that of Table $\Pi$ are customarily centered at $25^{\circ} \mathrm{C}$.
}
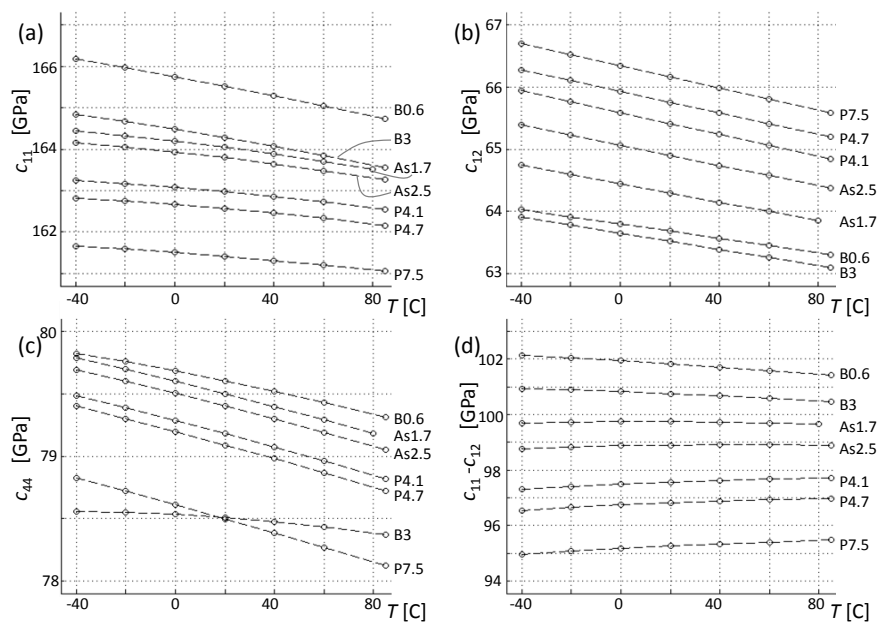

Figure 7. Elastic parameters $c_{11}, c_{12}, c_{44}$, and $c_{11}-c_{12}$ as a function of temperature and doping. The legends denote the dopant element types and the doping level, see Table 1 Dashed lines are second order fits to the $c_{i j}$ vs. $T$ data, and the fit coefficients are displayed in Fig. 8 and in Table III

\section{DISCUSSION}

\section{A. Comparison to literature}

Temperature coefficients measured in this work are compared to previously reported values in Fig. 8. Values for relatively weakly $\mathrm{n}$ - or $\mathrm{p}$-doped silicon, reported by Bourgeois et al. [13], appear to be in satisfactory agreement with our data; the data points near zero carrier concentration follow the trends observable from our data points. Data by Hall [8] differs somewhat from our results, in particular for the second order temperature coefficients. However, it should be noted that the temperature coefficients for Hall's data are based on graphical extraction of the published $c_{i j}(T)$ curves. 
(a)

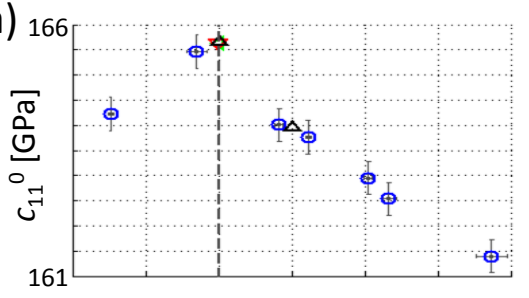

(d)

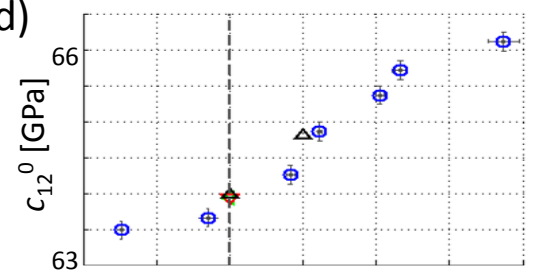

(g)

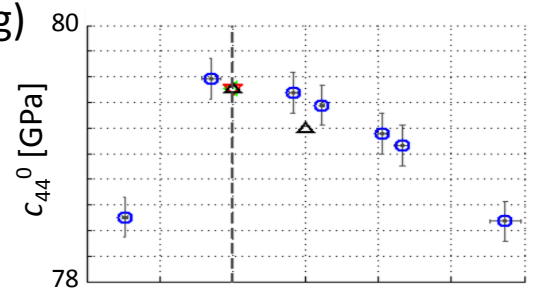

(j)

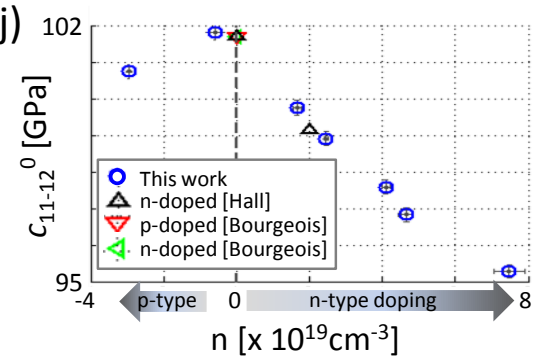

(b)

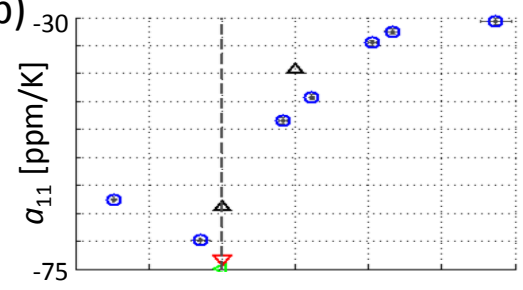

(e)

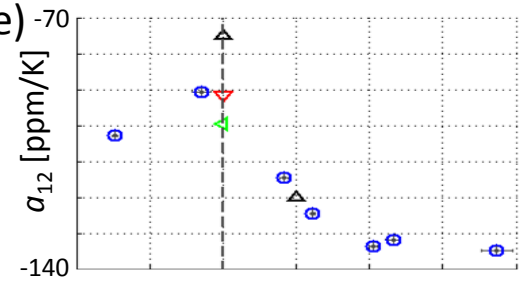

(h)

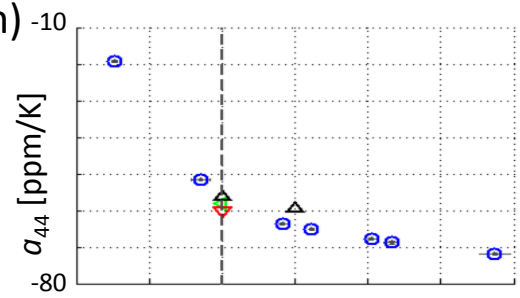

(k)

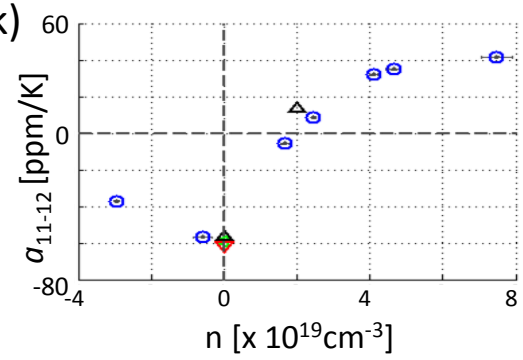

(c)

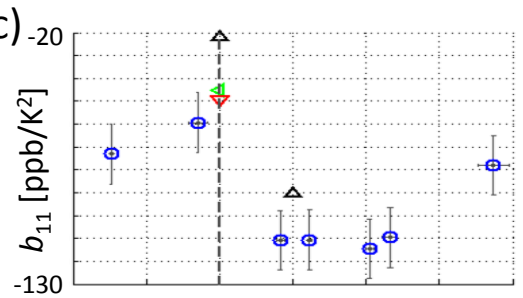

(f)

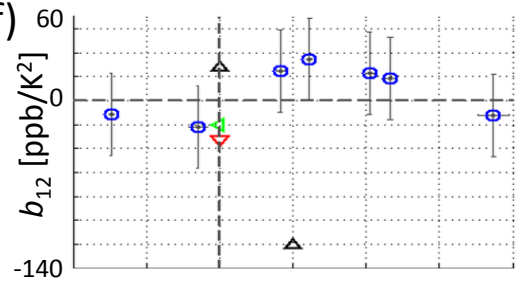

(i)

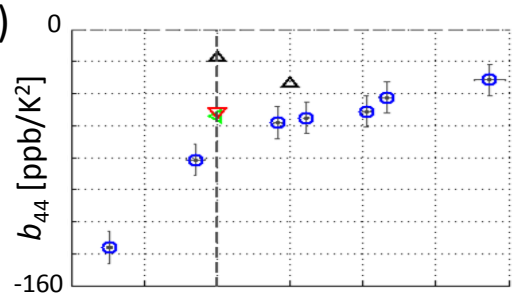

(I)

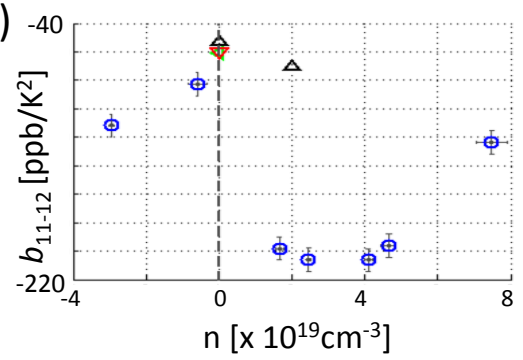

Figure 8. Temperature coefficients of the elastic parameters $c_{i j}$ as a function of carrier concentration $n$. Data from p-type doped wafers is represented with negative carrier concentrations. First, second and third column represent the constant terms $c_{i j}^{0}$, linear coefficients $\left(a_{i j}\right)$, and second-order coeffients $\left(b_{i j}\right)$ at $T=25^{\circ} C$, respectively, see 8. $c_{11-12}^{0}, a_{11-12}$ and $b_{11-12}$ are shorthands for the coefficients of $c_{11}-c_{12}$. Open blue circles are the experimentally determined values of this work. Numerical values are given in Table III Values reported in [13] are shown as red triangles pointing down (weak p-type doping) and as green triangles pointing left (weak n-type doping). Data reported by Hall in Ref. [8] was used for calculating data points shown as black triangles pointing up. Horizontal error bars indicate the carrier concentration ranges calculated from the resistivity specification for each wafer (see Table I). Vertical error bars are based on the error analysis of Section V-D

\section{B. Behavior of elastic coefficients with doping}

Figs. 8(a), (d), (g) and (j) show that the magnitude of the elastic parameters, i.e., the constant terms $c_{i j}^{0}$, are affected to within a few percent by increased doping over the tested wafers. These changes need to be taken into account when dimensioning resonator designs targeting a specific resonance frequency. While the offsets have a negligible effect for temperature compensation purposes, it has the potential to degrade the initial frequency accuracy within a set of devices on a single wafer or within a batch of wafers.

In general, it is seen that arsenic (data points with $0<$ $\left.n<4 \times 10^{19} \mathrm{~cm}^{-3}\right)$ and phosphorus $\left(n>4 \times 10^{19} \mathrm{~cm}^{-3}\right)$ as dopants do not stand out from the plots as separate groups, which supports the view of the effects being of mainly electronic origin[1].

The effects on silicon elastic properties from n-type doping are best observed in the shear elastic constant $c_{11}-c_{12}$ and, in particular, in its temperature coefficients $a_{11-12}$ and $b_{11-12}$. Fig. 8 (k) shows that the linear temperature coefficient $a_{11-12}$ crosses zero at approximately $n=2 \times 10^{19} \mathrm{~cm}^{-3}$. This is the effect of most practical importance for temperature compensation of MEMS applications, since many shear-type resonance modes are purely dependent on the $c_{11}-c_{12}$ term, and hence the linear temperature coefficient of frequency of such resonators can be brought to zero at this doping level. For example, the Lame $45^{\circ}$ mode of Fig 1 (a) is a mode whose frequency depends solely on $c_{11}-c_{12}$. When doping is further increased, $a_{11-12}$ reaches a level of over $+40 \mathrm{ppm} / \mathrm{K}$. The effect appears to saturate with increasing doping. A wide class of resonance modes, such as torsional, flexural and extensional modes have an amount of shear mode character, i.e., their frequency depends on $c_{11}-c_{12}$ with a large weight factor. Thus, their $f$ vs. $T$ curves are largely determined by the behavior of the $c_{11}-c_{12}$ term. The fact that $a_{11-12}$ attains 
Table III

VALUES OF TEMPERATURE COEFFICIENTS OF THE ElastiC PARAMETERS $c_{i j}$. CORRESPONDING DATA POINTS ARE PLOTTED IN Fig. 8 CONFIDENCE INTERVALS $\Delta c_{i j}^{0}, \Delta a_{i j}$ AND $\Delta b_{i j}$ ARE BASED ON THE ERROR ANALYSIS OF SECTION V-D

\begin{tabular}{|c|c|c|c|c|c|c|c|c|c|c|c|c|c|}
\hline dopant & $\begin{array}{c}\mathrm{n} \\
{\left[{ }^{*} 10^{19} \mathrm{~cm}^{-3}\right]}\end{array}$ & $\begin{array}{l}\mathrm{C}_{11}{ }^{0} \\
{[\mathrm{GPa}]}\end{array}$ & $\begin{array}{c}\mathrm{a}_{11} \\
{[\mathrm{ppm} / \mathrm{K}]}\end{array}$ & $\begin{array}{c}b_{11} \\
{\left[p p b / K^{2}\right]}\end{array}$ & $\begin{array}{l}\mathrm{c}_{12}{ }^{0} \\
{[\mathrm{GPa}]}\end{array}$ & $\begin{array}{c}\mathrm{a}_{12} \\
{[\mathrm{ppm} / \mathrm{K}]}\end{array}$ & $\begin{array}{c}b_{12} \\
{\left[p p b / K^{2}\right]}\end{array}$ & $\begin{array}{l}\mathrm{C}_{44}{ }^{0} \\
{[\mathrm{GPa}]}\end{array}$ & $\begin{array}{c}\mathrm{a}_{44} \\
{[\mathrm{ppm} / \mathrm{K}]}\end{array}$ & $\begin{array}{c}\mathrm{b}_{44} \\
{\left[\mathrm{ppb} / \mathrm{K}^{2}\right]}\end{array}$ & $\begin{array}{c}\mathrm{c}_{11}{ }^{0}-\mathrm{c}_{12}{ }^{0} \\
{[\mathrm{GPa}]}\end{array}$ & $\begin{array}{c}\mathrm{a}_{11-12} \\
{[\mathrm{ppm} / \mathrm{K}]}\end{array}$ & $\begin{array}{c}b_{11-12} \\
{\left[\mathrm{ppb} / \mathrm{K}^{2}\right]}\end{array}$ \\
\hline B & 3.0 & 164.2 & $\begin{array}{c}-62.5 \\
\end{array}$ & -73 & 63.5 & -102.9 & -11 & 78.5 & -19.3 & -136 & 100.7 & -37.1 & -112 \\
\hline As & 1.7 & 164.0 & -48.5 & -111 & 64.3 & -114.7 & 25 & 79.5 & -63.7 & -58 & 99.7 & -5.8 & -198 \\
\hline As & 2.5 & 163.8 & -44.2 & -111 & 64.9 & -124.6 & 34 & 79.4 & -65.1 & -55 & 98.9 & 8.5 & -206 \\
\hline P & 4.1 & 163.0 & -34.5 & -115 & 65.4 & -133.7 & 22 & 79.2 & -67.8 & -51 & 97.6 & 31.9 & -206 \\
\hline $\mathrm{P}$ & & $\Delta \mathrm{c}_{11}{ }^{0}$ & $\Delta \mathrm{a}_{11}$ & $\Delta \mathrm{b}_{11}$ & $\Delta \mathrm{c}_{12}{ }^{0}$ & $\Delta \mathrm{a}_{12}$ & $\Delta \mathrm{b}_{12}$ & $\Delta \mathrm{c}_{44}{ }^{0}$ & $\Delta \mathrm{a}_{44}$ & $\Delta \mathrm{b}_{44}$ & $\Delta\left(\mathrm{c}_{11}{ }^{0}-\mathrm{c}_{12}{ }^{0}\right)$ & $\Delta \mathrm{a}_{11-12}$ & $\Delta \mathrm{b}_{11-12}$ \\
\hline \multicolumn{2}{|c|}{ Total uncertainty (rms sum) } & \pm 0.3 & \pm 0.7 & \pm 12 & $\overline{c \pm 0.1}$ & \pm 1.5 & \pm 33 & \pm 0.2 & \pm 0.4 & \pm 10 & \pm 0.2 & \pm 0.3 & \pm 7 \\
\hline \multicolumn{2}{|c|}{$E_{1}:$ frequency error } & \pm 0.3 & \pm 0.39 & \pm 9.4 & \pm 0.1 & \pm 1.20 & \pm 28.5 & \pm 0.2 & \pm 0.16 & \pm 3.6 & \pm 0.2 & \pm 0.16 & \pm 3.5 \\
\hline \multicolumn{2}{|c|}{$E_{2}:$ temperature error } & & \pm 0.26 & \pm 6.6 & & \pm 0.64 & \pm 17.1 & & \pm 0.34 & \pm 9.1 & & \pm 0.20 & \pm 5.6 \\
\hline \multicolumn{2}{|c|}{$E_{3}:$ linearization point error } & & \pm 0.54 & \pm 0.8 & & \pm 0.69 & \pm 1.1 & & \pm 0.01 & \pm 0.0 & & \pm 0.02 & \pm 0.0 \\
\hline
\end{tabular}

relatively large positive values enables first-order temperature compensation of such modes. These aspects are discussed in more detail in Ref. [6].

Fig. 8(1) shows that the second order coefficient $b_{11-12}$ is negative for all studied doping levels, with a maximum deviation from zero of approximately $-200 \mathrm{ppb} / \mathrm{K}^{2}$. This would translate to a $250 \mathrm{ppm}$ frequency deviation over a range of $100^{\circ} \mathrm{C}$. Importantly, one finds that the second order coefficient $b_{11-12}$ appears to approach zero when n-type doping level is above $n=4.1 \times 10^{19} \mathrm{~cm}^{-3}$. This suggests a possibility of a flat or positive second order response at high enough doping, motivating further investigation of n-type doping beyond $10^{20} \mathrm{~cm}^{-3}$.

The key effect to temperature compensation with p-type doping is observable in Fig. 8 (h). The linear temperature coefficient $a_{44}$ approaches zero with increasing p-type dopant concentration. However, zero level is not yet crossed with the highest doping level of $3 \times 10^{19} \mathrm{~cm}^{-3}$. The second order coefficient $b_{44}$ is seen to grow in magnitude with increased p-type doping. N-type doping is observed to have a relatively small effect on coefficients $a_{44}$ and $b_{44}$.

\section{Reliability of elastic parameter extraction}

Seven data points were used for the extraction of the three unknown elastic parameters $c_{i j}(T)$ at each temperature. Hence, the reliability of the method can be assessed by comparing the measured frequency data to the corresponding numerical estimates obtained from FEM simulations which use the solved parameters $c_{i j}(T)$ as an input. First, Fig. 9 (a) shows the correspondence of measured and simulated resonance frequencies at $T_{0}=20^{\circ} \mathrm{C}$, where $c_{i j}\left(T_{0}\right)$ has been obtained from a fit to (2). The difference is within $\pm 1000 \mathrm{ppm}$.

Correspondingly, the quality of the least squares fit of (7) can be judged from the overlap of the measured and simulated data, exemplified in Fig. 5(e). This is seen in closer detail in Fig. 9 b), where the difference between the measured relative frequency changes $\delta f_{k}^{\mathrm{exp}}(T)$ and the corresponding theoretical estimates $\delta f_{k}^{\text {th }}\left(c_{i j}(T)\right)$ has been plotted for all modes on all wafers. Maximum deviation between the measured and simulated data points was below $25 \mathrm{ppm}$ for all seven resonance modes on all wafers, which speaks for the reliability of the extraction method. It should be noted that without correction of the angular misalignments (Section III-C), the least squares method would have resulted in errors up to $60 \mathrm{ppm}$.

Validity of the linearization step needed for the least square method was confirmed: Frequency changes from approximation of (3) were calculated for each of the extracted elastic parameters $c_{i j}(T)$, and compared with the non-linearized counterpart $\delta f_{k}^{\text {th }}\left(c_{i j}(T)\right)$. Linearization error was found to be less than $5 \mathrm{ppm}$ for all cases.

Based on the above analysis, we expect that by using the extracted elastic parameters, one can estimate the frequency of an arbitrary resonance mode, fabricated on a wafer with similar carrier concentration as in our experiments, with following accuracies:

- Absolute frequency of a resonator can be predicted with \pm 1000 ppm accuracy.

- Thermal drift over a temperature range of $T=-40 \ldots+$ $85^{\circ} \mathrm{C}$ can be predicted with $\pm 25 \mathrm{ppm}$ accuracy.

\section{Accuracy of temperature coefficients of $c_{i j}$ parameters}

While the analysis of the previous section provides a way to establish a confidence level on the resonance frequencies that can be calculated from the extracted elastic parameters of this work, one can obtain also estimates for the accuracy of the temperature coefficients of elastic constants. Let us denote these confidence intervals as $\Delta c_{i j}^{0}, \Delta a_{i j}$ and $\Delta b_{i j}$. They are listed in Table III and also shown as vertical error bars in Fig. 8

For $\Delta c_{i j}^{0}$, an upper limit of $\pm 2000 \mathrm{ppm}$ is obtained by starting from the above discussed absolute frequency accuracy 


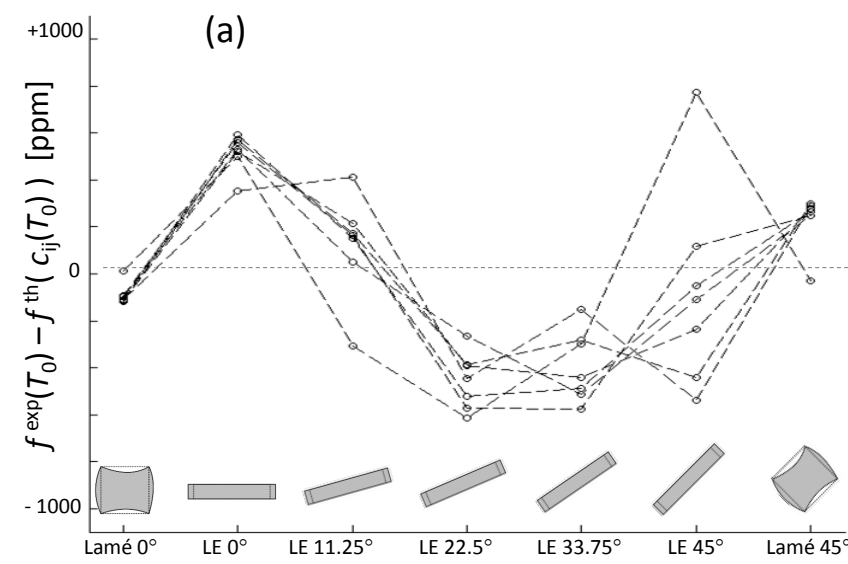

(b)

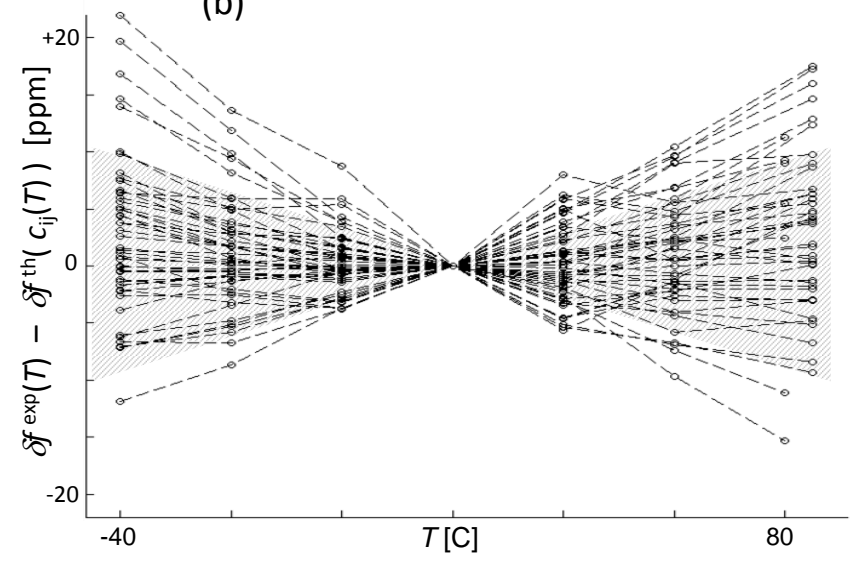

Figure 9. (a) Difference between measured frequencies $f_{k}^{\exp }\left(T_{0}\right)$ and theoretical estimates $f_{k}^{\text {th }}\left(c_{i j}\left(T_{0}\right)\right)$ at $T_{0}=20^{\circ} \mathrm{C}$ for all resonance modes on all wafers. Theoretical estimates are based on $c_{i j}\left(T_{0}\right)$, which are the fitted elastic parameters obtained through numerical minimization of 2. (b) Difference between the measured relative frequency changes $\delta f_{k}^{\exp }\left(\frac{2}{T}\right)$ and the corresponding theoretical estimates $\delta f_{k}^{\text {th }}\left(c_{i j}\left(T_{0}\right)+\delta c_{i j}(T)\right)$ for all resonance modes on all wafers. Theoretical estimates are calculated using $\delta c_{i j}(T)$ that have been fitted using 7 . The shaded region illustrates the frequency measurement uncertainty that has been assumed in error analysis of Section $\mathrm{V}-\mathrm{D}$

of $\pm 1000 \mathrm{ppm}$, and by applying (1). Other potential error sources of smaller magnitude are:

- The mass of dopant atoms differs from that of silicon. Assuming that the volume of the crystal stays constant the maximal density change is less than $200 \mathrm{ppm}$, which would be reflected as a similar inaccuracy in $c_{i j}^{0}$.

- The dimensions of the resonators may vary slightly from the designed measures due to potential mask bias and imperfections in DRIE etching. A conservative estimate for the lateral dimension change of $\pm 0.1 \mu \mathrm{m}$ of the resonators would deviate the resonance frequency approximately by $\pm 300 \mathrm{ppm}$, and thus have an effect of $\pm 600 \mathrm{ppm}$ on $c_{i j}^{0}$.

- Thickness variation of $\pm 2 \mu \mathrm{m}$ of the device layer would have a very small effect on frequencies of the resonators: FEM analysis indicated that the frequencies of the LE modes stay within $\pm 20 \mathrm{ppm}$, and changes are even smaller for the Lamé modes.

To assess the inaccuracy of the first and second order temperature coefficients of the elastic parameters, a Monte Carlo approach was used to simulate the effect of several error sources. A large number of copies of the experimental data sets (of Fig. 5] were taken, and perturbed according to following sources of uncertainty, labeled as $E_{1} \ldots E_{5}$ :

$E_{1}$ : Relative frequencies were deviated by $\delta f \times$ $|\Delta T| / \Delta T_{\max }$, where $\delta f$ was taken from a normally distributed population with a standard deviation of $10 \mathrm{ppm}, \Delta T$ was defined as $T-20^{\circ} \mathrm{C}$, and $\Delta T_{\max }$ was set to $65^{\circ} \mathrm{C}$. The distribution is visualized by the shaded region of Fig. 9 b)). This way a distribution corresponding to the observed errors in relative frequencies was reproduced.

$E_{2}$ : The accuracy specified for the temperature controller and chuck was taken into account by deviating the temperature points by $\delta T$ taken from a normally distributed population with a standard deviation of $0.5^{\circ} \mathrm{C}$.

$E_{3}$ : Sensitivities of (6) were evaluated at the linearization points $c_{i j}^{0}$, which was estimated above to have an uncertainty within $\pm 2000 \mathrm{ppm}$. Error caused by this was simulated by perturbing the linearization points accordingly.

$E_{4}$ : Thermal expansion was assumed constant in the calculations, and our measurements suggested this to hold for linear thermal expansion within a $\pm 7 \%$ error marginal (V-E). The thermal expansion effect in (4) was perturbed to take this uncertainty into account.

$E_{5}$ : Thickness of the devices deviated from the nominal thicknesses used in the simulations. Sensitivities of 6 were perturbed to take into account a thickness variation of $\pm 2 \mu \mathrm{m}$.

Extraction of the elastic parameters $c_{i j}(T)$ was performed on the perturbed data sets, identically to as it was done on the real measurement data, and distributions of $a_{i j}$ and $b_{i j}$ were obtained. Confidence intervals $\Delta a_{i j}$ and $\Delta b_{i j}$ were calculated for each error source $E_{1} \ldots E_{5}$ separately, and the total effect was estimated as the rms sum. Values for $E_{1}$ and $E_{2}$ were obtained as standard deviations the $a_{i j} / b_{i j}$ distributions, while the full range was used for $E_{3} \ldots E_{5}$. Inaccuracy of the first order coefficient $a_{i j}$ was found to range from $\Delta a_{11-12}= \pm 0.3 \mathrm{ppm} / \mathrm{K}$ to $a_{12}= \pm 1.5 \mathrm{ppm} / \mathrm{K}$. Correspondingly, error of the second order coefficient was seen to vary from $\Delta b_{11-12}= \pm 7 \mathrm{ppb} / \mathrm{K}^{2}$ to $\Delta b_{12}= \pm 33 \mathrm{ppb} / \mathrm{K}^{2}$. Error in measured frequencies $\left(E_{1}\right)$ and inaccuracy of temperature $\left(E_{2}\right)$ were major sources of uncertainty for all $a_{i j} / b_{i j}$ parameters, and the linearization point error $\left(E_{3}\right)$ was a top contributor for $a_{11}$ and $a_{12}$.

\section{E. Doping independency of thermal expansion}

The procedure for extracting the elastic parameters relied on the assumption that thermal expansion of (4) would be insensitive to doping. To our knowledge, effects from heavy doping to thermal expansion of silicon have not been studied experimentally. For verification, mechanical dilatometry was used for measuring the thermal expansion of samples with similar doping levels as wafers B3, As1.7 and P7.5. The linear thermal expansion coefficient $\alpha_{1}$ was found to be constant within the $\pm 7 \%$ error marginal of the measurement. 


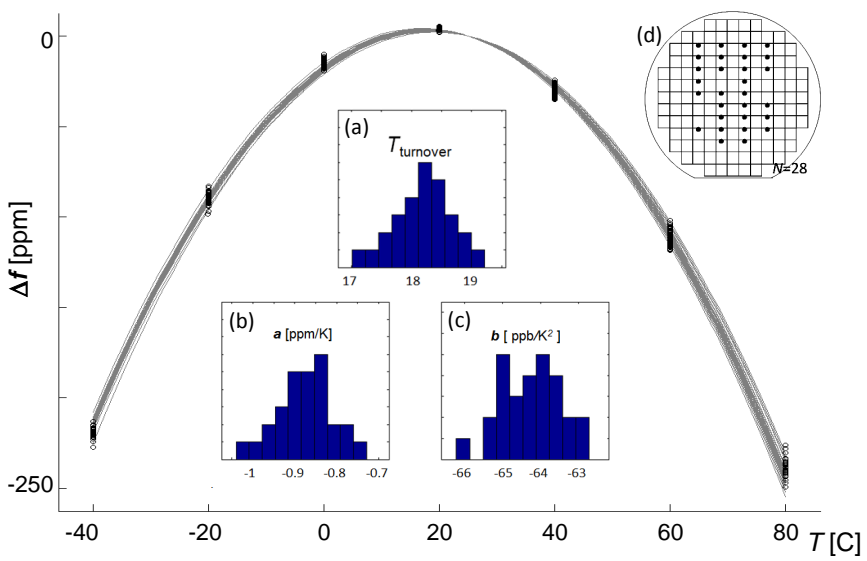

Figure 10. Superposed $f$ vs. $T$ curves of 28 square extensional resonator samples similar to that of Ref. [5]. Measurements are shown as black open circles, while second order polynomial fits to the data are denoted with gray lines. The wafer has been doped with phosphorus to a concentration of $n \sim$ $5 \times 10^{19} \mathrm{~cm}^{-3}$. Histograms (a), (b) and (c) illustrate the distribution of the turnover temperature, and the first/second order temperature coefficients of frequency, respectively. Wafer map (d) shows the location of the measured devices on the wafer.

\section{F. Manufacturability of temperature compensated MEMS res- onators}

Eventual manufacturability of silicon resonators whose temperature compensation is based on degenerate doping crucially depends on the statistical variations of the $f$ vs. $T$ curves among devices fabricated on a single wafer or on a batch of wafers. This aspect was addressed by studying a set of $\sim 30$ square extensional mode resonators of Ref. [5], which were fabricated on a wafer with a specification similar to that of wafer P4.7 of this work. The $f$ vs. $T$ curves of the devices are shown in Fig. 10. These devices were temperature compensated to first order with their turnover temperatures near $20^{\circ} \mathrm{C}$. The overall frequency drift over the whole temperature range of $120 \mathrm{C}^{\circ}$ stays within $250 \mathrm{ppm}$, and maximum deviation between samples is approximately $20 \mathrm{ppm}$. One should note that the data of this example is from devices on a Czochralski grown wafer, where the doping level may vary $\pm 5 \%$ within the wafer. A better control of doping level is achievable with diffusion based doping, or with epitaxially grown silicon, where doping can be controlled during the crystal growth process.

\section{CONCLUSION}

Elastic constants $c_{11}, c_{12}$ and $c_{44}$ of degenerately doped silicon were studied experimentally as a function of the doping level and temperature. First and second order temperature coefficients of the elastic constants were extracted from measured resonance frequencies of a set of MEMS resonators fabricated on wafers with varied doping.

The linear temperature coefficient of the shear elastic parameter $c_{11}-c_{12}$ was found to be zero at n-type doping level of $n \sim 2 \times 10^{19} \mathrm{~cm}^{-3}$. It was observed to increase to over $+40 \mathrm{ppm} / \mathrm{K}$ with higher level of doping, which implies that the frequency of many types of resonance modes, including extensional bulk modes and flexural modes, can be temperature compensated to first order. The second order temperature coefficient of $c_{11}-c_{12}$ was found to decrease by $40 \%$ in magnitude when n-type doping was increased from 4.1 to $7.5 \times 10^{19} \mathrm{~cm}^{-3}$, suggesting a further reduction of the second order effect with increased doping.

It was found that the frequency drift of an arbitrary silicon resonator design, fabricated on a wafer with doping level similar to those investigated in this work, can be estimated with an accuracy of $\pm 25 \mathrm{ppm}$ over a temperature range of $T=-40 \ldots 85^{\circ} \mathrm{C}$ using the elastic parameters of this work. Absolute frequency can be calculated with an accuracy of \pm 1000 ppm.

\section{ACKNOWLEDGMENTS}

The authors would like to acknowledge the Finnish Funding Agency for Technology and Innovation (Tekes), Okmetic Oyj, Murata Electronics and Micro Analog Systems for funding. Okmetic Oyj is acknowledged for providing the silicon wafers. A.J. acknowledges funding from the Academy of Finland, and wishes to thank Arto Nurmela for help in the measurements. Roger Morrell is thanked for performing the thermal expansion measurements.

\section{REFERENCES}

[1] R. W. Keyes, "Electronic effects in the elastic properties of semiconductors," in Solid State Physics: Advances in Research and Applications, ed. by F. Seitz and D. Turnbull. Academic Press, 1967, vol. Volume 20, pp. 37-90.

[2] F. S. Khan and P. B. Allen, "Temperature dependence of the elastic constants of p+ silicon," Physica Status Solidi (b), vol. 128, no. 1, pp. 31-38, 1985.

[3] A. K. Samarao, G. Casinovi, and F. Ayazi, "Passive TCF compensation in high q silicon micromechanical resonators," in IEEE International Conference on Micro Electro Mechanical Systems (MEMS 2010), Hong Kong, Jan. 2010, pp. 116-119.

[4] A. Hajjam, A. Rahafrooz, and S. Pourkamali, "Sub-100ppb/C temperature stability in thermally actuated high frequency silicon resonators via degenerate phosphorous doping and bias current optimization," in Proc. IEEE International Electron Device Meeting (IEDM), 2010, pp. 7.5 .1 7.5.4.

[5] T. Pensala, A. Jaakkola, M. Prunnila, and J. Dekker, "Temperature compensation of silicon MEMS resonators by heavy doping," in Proc. IEEE International Ultrasonics Symposium, 2011, pp. 1952-1955.

[6] A. Jaakkola, M. Prunnila, and T. Pensala, "Temperature compensated resonance modes of degenerately n-doped silicon MEMS resonators," in Frequency Control Symposium (FCS), 2012 IEEE International, May 2012, pp. $1-5$.

[7] E. J. Ng, C. H. Ahn, Y. Yang, V. A. Hong, C.-F. Chiang, E. Ahadi, M. W. Ward, and T. W. Kenny, "Localized, degenerately doped epitaxial silicon for temperature compensation of resonant MEMS systems," in Transducers 2013, Barcelona, Spain, 2013, pp. 2419-2422.

[8] J. J. Hall, "Electronic effects in the elastic constants of n-type silicon," Physical Review, vol. 161, no. 3, p. 756, 1967.

[9] K. G. Lyon, G. L. Salinger, C. A. Swenson, and G. K. White, "Linear thermal expansion measurements on silicon from 6 to $340 \mathrm{k}$," Journal of Applied Physics, vol. 48, no. 3, pp. 865-868, Mar. 1977.

[10] "Standard practice for conversion between resistivity and dopant density for boron-doped, phosphorus-doped, and arsenic-doped silicon," in Annual Book of ASTM Standards, F 723-99. West Conshohocken, PA: American Society for Testing and Materials, 2000, pp. 275-291.

[11] H. Luoto, K. Henttinen, T. Suni, J. Dekker, J. Mäkinen, and A. Torkkeli, "MEMS on cavity-SOI wafers," Solid-State Electronics, vol. 51, pp. 328-332, 2007.

[12] V. Kaajakari, J. Kiihamäki, A. Oja, S. Pietikäinen, V. Kokkala, and H. Kuisma, "Stability of wafer level vacuum encapsulated single-crystal silicon resonators," Sensors and Actuators A: Physical, vol. 130, pp. 42-47, 2006. 
[13] C. Bourgeois, E. Steinsland, N. Blanc, and N. F. de Rooij, "Design of resonators for the determination of the temperature coefficients of elastic constants of monocrystalline silicon," in IEEE International Frequency Control Symposium, 1997, pp. 791-799. 